\section{Cureus}

Received 12/22/2015

Review began 01/22/2016

Review ended 03/23/2016

Published 04/11/2016

\section{(c) Copyright 2016}

Shaikh et al. This is an open access article distributed under the terms of the Creative Commons Attribution License CC-BY 3.0., which permits unrestricted use, distribution, and reproduction in any medium, provided the original author and source are credited.

\title{
Molecular Imaging in Genetic Medicine
}

\author{
Faiq Shaikh ${ }^{1}$, Ayden Jacob ${ }^{2}$, Frederick Van Gestel ${ }^{3}$, Shahriar Yaghoubi ${ }^{4}$ \\ 1. Institute of Computational Health Sciences, University of California San Francisco 2. Interventional \\ Radiology and Oncology, UCSF School of Medicine 3. 3rd Master Medicine, Catholic University of Leuven \\ 4. Medical Affairs, United Therapeutics
}

$\square$ Corresponding author: Faiq Shaikh, faiq.shaikh@hotmail.com

Disclosures can be found in Additional Information at the end of the article

\section{Abstract}

The field of biomedical imaging has made significant advances in recent times. This includes extremely high-resolution anatomic imaging and functional imaging of physiologic and pathologic processes as well as novel modalities in optical imaging to evaluate molecular features within the cellular environment. The latter has made it possible to image phenotypic markers of various genotypes that are implicated in human development, behavior, and disease. This article discusses the role of molecular imaging in genetic and precision medicine.

Categories: Genetics, Radiology

Keywords: molecular, imaging, genetic, reporter gene, medicine, optical

\section{Introduction And Background}

Reporter genes (RGs) are responsible for encoding proteins that can be rapidly and sensitively assayed as surrogate markers when fused with regulatory regions of the gene of interest [1]. They are used to study promoter/enhancer elements that affect expression and messenger ribonucleic acid (mRNA) sequences that control message stability and regulate translation efficiency [1-2]. That is made possible in living subjects through the development of highly advanced molecular imaging techniques within the domain of optical imaging [2]. RGs are increasingly being used for imaging-based evaluation and monitoring of gene and cell therapy, stem cell therapy, and immune modulation therapy as they provide the means to determine the location, magnitude, and persistence of gene expression and monitor cell kinetics (cell biodistribution, quantity, proliferation, survival, differentiation, and function) in living organisms [3-4].

\section{Review}

Reporter gene (RG) imaging involves non-invasive, repetitive, and sometimes quantitative analysis of reporter gene expression [5]. The process evolves from RG transcription into enzyme/receptor/transporter production, leading to entrapment of the imaging reporter probe, which then imparts the signal for imaging. This may be a radioisotope/photochemical reaction/magnetic resonance metal cation based on the imaging modality used [1-2]. Currently available non-RG-based molecular imaging techniques depend on the direct interaction of imaging probes with their cellular targets, causing retention of imaging probe within tissues, such as radiolabeled ligands and radiolabeled antibodies. One such example is that of $11 \mathrm{C}-$ WAY-100635 (radioligand for the 5-HT1A receptor) or iodine-124 radiolabeled anticarcinoembryonic antigen minibody [6].

RG imaging provides a non-invasive and highly specific means of detecting several molecular 


\section{Cureus}

processes, such as gene expression or protein-protein interactions. This enables us to optimize drug and gene therapy, assess disease progression at a molecular level, and allow rapid, reproducible, and quantitative monitoring of time-dependent influences on gene products [3, 7]. Optical imaging involves techniques, such as fluorescence and bioluminescence, to detect visible light that is generated in living cells. Fluorescence imaging uses proteins that emit photons as a result of excitation with those of a shorter wavelength and can be used to microscopically track the subcellular distribution of various molecules and monitor expression of gene products. Bioluminescence depends on the enzymatic reaction between a luciferase enzyme (firefly, Renilla) and its substrate (D-luciferin, coelenterazine) to produce visible light that is detected and quantified using highly sensitive cooled charge-coupled device (CCD) cameras (Figure 1) [8-9].
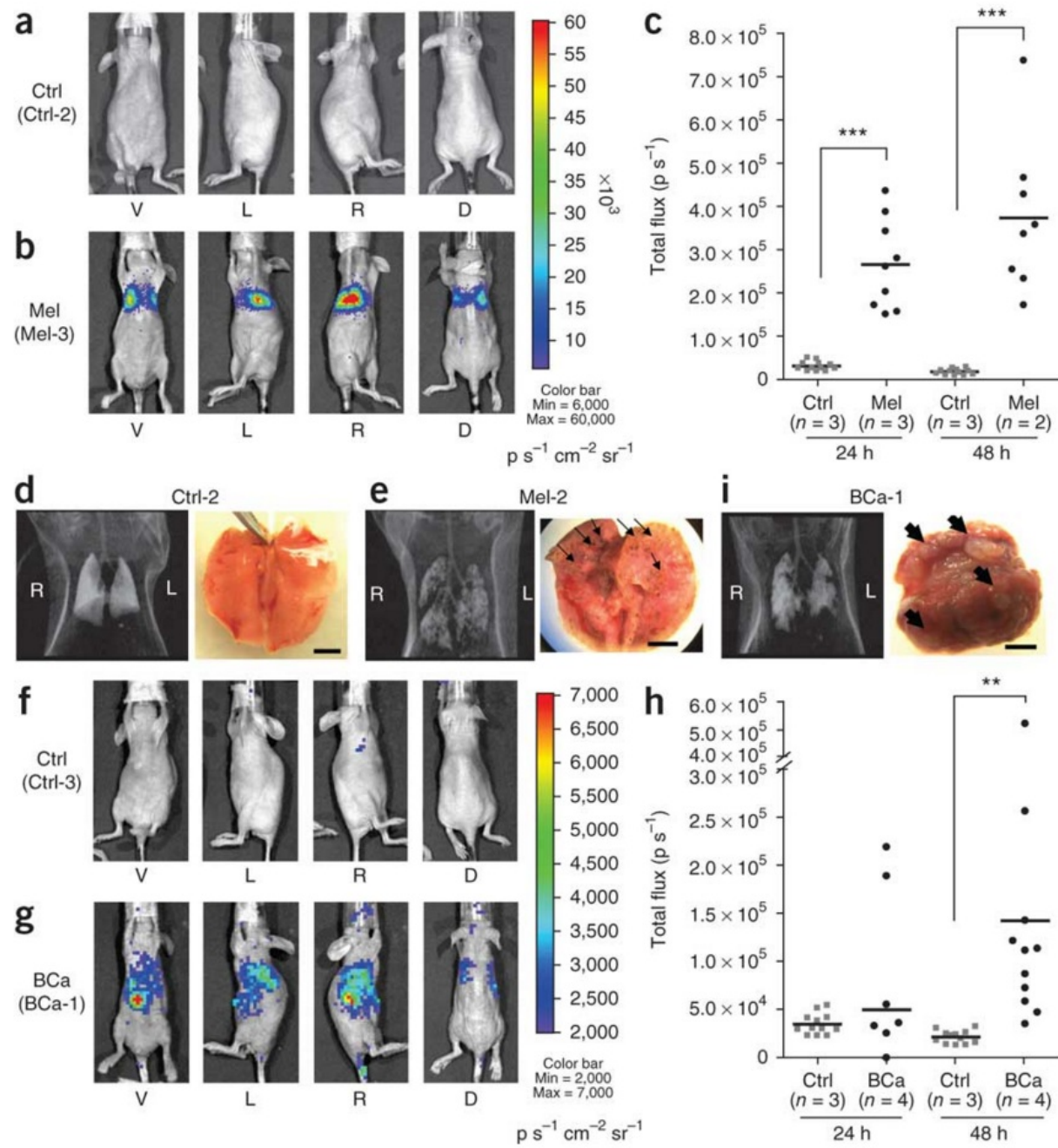

\section{FIGURE 1: Bioluminescence imaging in cancer models}

Bioluminescence imaging using firefly luciferase expression in a (a) control mouse model, (b) mouse melanoma model at 24 and 48 hrs after injection of pPEG-Luc-PEI polyplex, (c) flux graph, along with their respective (d-e) gross specimen photographs and CT images; bioluminescence imaging using firefly luciferase expression in a (f) control mouse model, $(g)$ mouse breast cancer model at 24 and 48 hrs after injection of pPEG-Luc-PEI polyplex, (i) flux graph, along with their respective (i) gross specimen photo and CT scan. (Used with permission from Pomper, et al.: Tumor-specific imaging through progression elevated gene-3 promoterdriven gene expression. Nature Medicine 2011 17:123-129) 


\section{Cureus}

There have been significant advances in magnetic resonance imaging (MRI) and ultrasonography-based imaging of subcellular processes. MRI-based probes, such as $\beta$-gal + activated contrast agent, ferritin, tyrosinase, magA, plasma membrane-bound peptides, and engineered transferrin receptors (ETfR) have been introduced to monitor gene expression patterns in gene therapy and to analyze processes of cell-based regenerative therapies within oncology, cardiology, and neurology [10]. Acoustically analyzable perfluorocarbon nanoparticles have been used to detect specific receptors as well [11].

In the field of Nuclear Medicine, radioisotopes that emit high energy particles like gamma rays and positrons to label probes are used, which readily penetrate tissue and can be detected outside the body. Gamma- or positron-emitting isotopes can be incorporated into molecular probes, such as receptor-specific ligands and enzyme-specific substrates. Imaging agents, such as 1-(2-deoxy-2-fluoro-1-D-arabinofuranosyl)-5-iodouracil (FIAU), have been used to image the expression of their respective RGs using positron emission tomography (PET) or single photon emission computed tomography (SPECT), depending on the labelled radiotracer (iodine-124 for PET; iodine-123 or -125 for SPECT) (Figures 2-3). These RGs may encode enzymes that phosphorylate specific PET/SPECT reporter probes that lead to their intracellular entrapment, or encode receptors that can bind to specific probes, or encode cell membrane transporters that facilitate flow and accumulation of these specific probes into cells [12-13]. 


\section{Cureus}

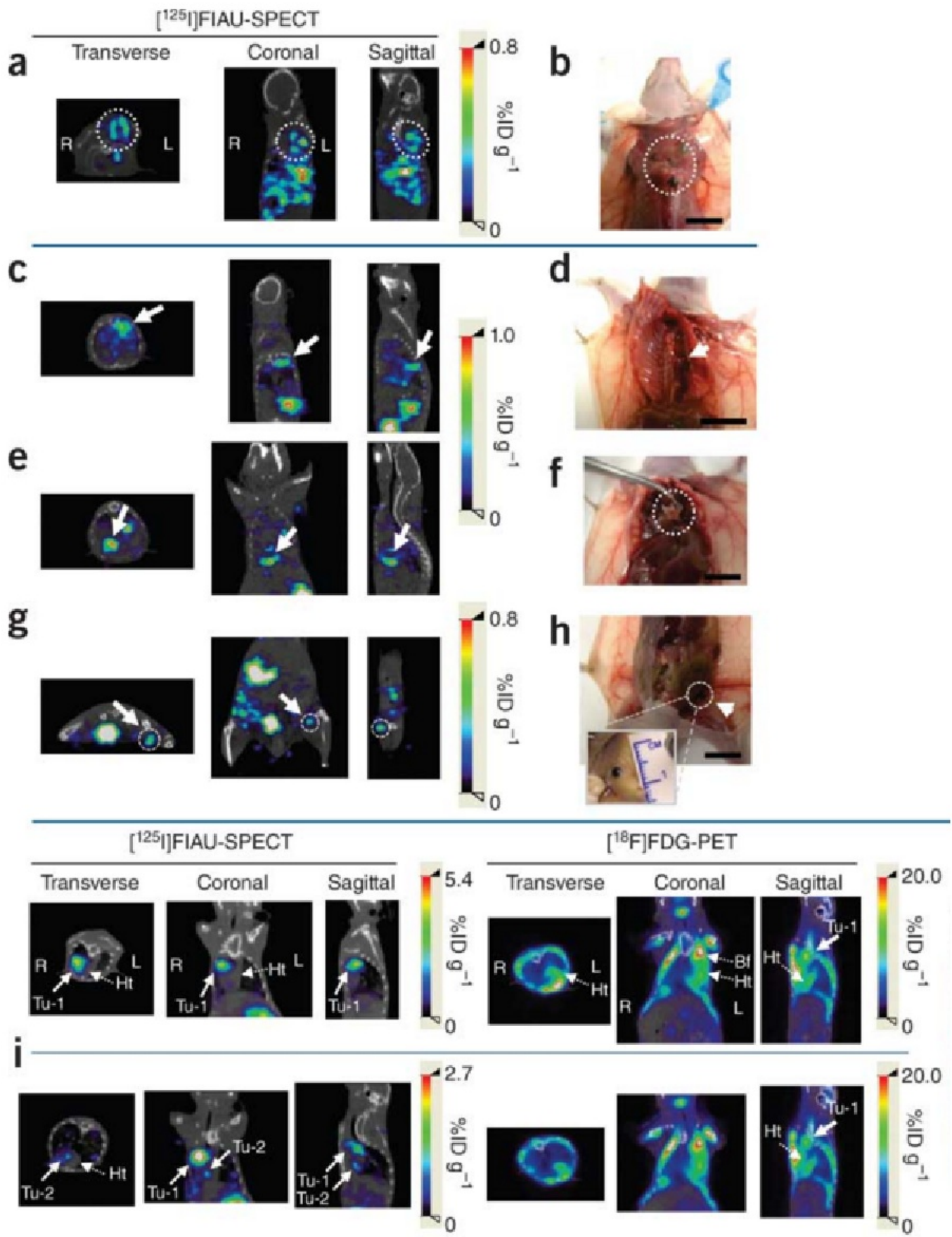

\section{FIGURE 2: 125I-FIAU SPECT vs. 18F-FDG PET imaging}

Comparison of PEG-3 promoter mediated 125I-FIAU SPECT (with corresponding specimen photographs; a-h) and (i) 18F-FDG PET imaging in a mouse breast cancer model. FIAU identified two tumor sites obscured by physiologic distribution of FDG on PET imaging. (Used with permission from Pomper, et al.: Tumor-specific imaging through progression elevated gene-3 promoter-driven gene expression. Nature Medicine 2011 17:123-129) 


\section{Cureus}

a
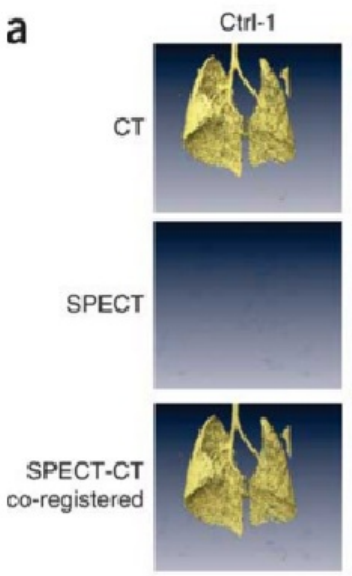

b
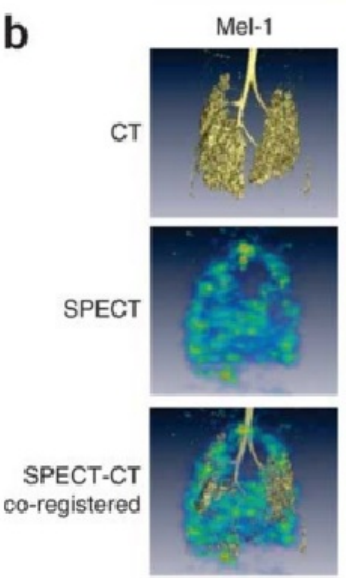
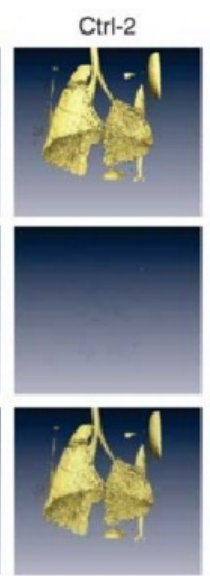

Mel-2
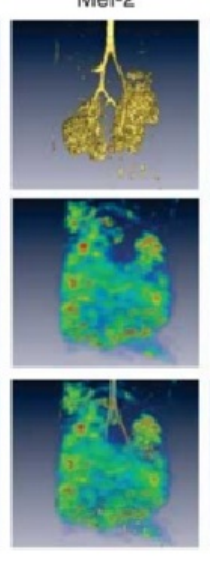
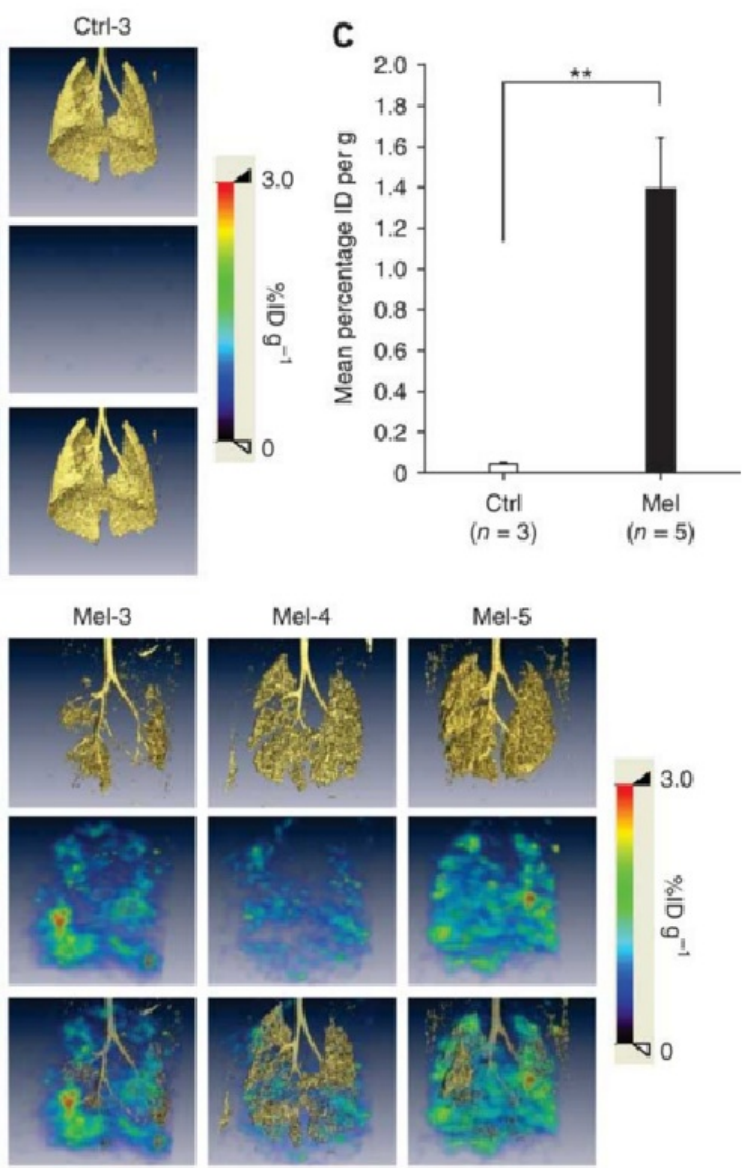

\section{FIGURE 3: Pulmonary metastasis identified by 125I-FIAU SPECT/CT imaging}

CT, SPECT, and fused SPECT/CT 125I-FIAU imaging after injection of pPEG-HSVtk-PEI in (a) control vs. (b) mouse melanoma model. (Used with permission from Pomper, et al.: Tumorspecific imaging through progression elevated gene-3 promoter-driven gene expression. Nature Medicine 2011 17:123-129)

PET/SPECT reporter probes can be either human gene-based or virus/bacteria-based. Herpes simplex virus Type 1 thymidine kinase (HSV1-tk) and its mutant derivatives are the most extensively studied and applied viral-based reporter probes. Immunogenicity of viral-based probes can be detrimental to adoptively transferred therapeutic cells expressing them, shortening the duration of their expression, or eradicating the therapeutic cell expressing them [14]. Conversely, human gene-based IRGs may accumulate in cells that express the endogenous gene, or may mimic as the endogenous gene, causing perturbation in the functioning of the cells in which it is expressed. Human thymidine kinase 2 (hmtk2) is an example of a human gene product which is ubiquitously expressed in the mitochondria of mammalian cells. It is inaccessible to uracil nucleoside analogs and has a non-immunogenic truncated version produced in the cytoplasm without nonspecific accumulation of its probes $[2,15]$.

Molecular imaging techniques also provide ways to study the whole-body kinetics of therapeutic cells (TCs), allowing for monitoring presence, location, quantity, proliferation, survival, and status of TCs in animals or patients at any desired time-point following their administration, such as seen in luciferase-based imaging here (Figures 4-5). Whole-body $18 \mathrm{~F}-$ FHBG PET scans have been performed to demonstrate above-background signal at the site of 


\section{Cureus}

cytolytic T-cell infusions, which revealed trafficking of these cells to a remote recurrent tumor in the patient's corpus callosum [16].
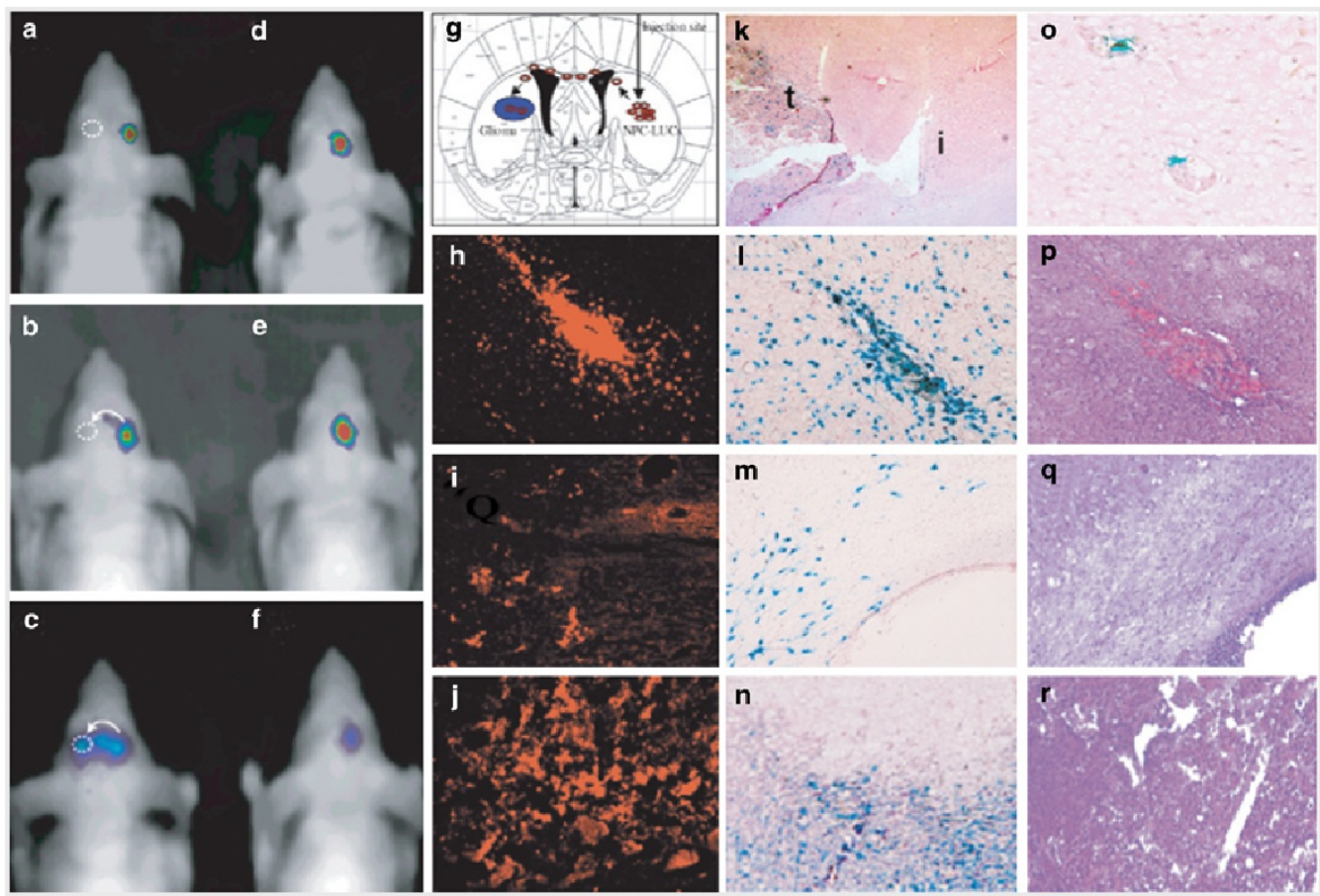

\section{FIGURE 4: Bioluminescence imaging demonstrating parenchymal migration of luciferase-expressing cells}

Parenchymal migration of NPC-LUCs expressing Fluc (NFC-Luc) cell that was implanted into (a-c) the right hemisphere of either mice bearing Gli36 tumors in the left hemisphere or (d-f) control mice which did not have tumors. Time intervals are represented at (a) Day 0, (b) 1 week, and (c) 2 weeks. Migration towards the tumor (dotted circle) was first noted after 1 week and migration across the midline was evident at 2 weeks. Images d-f are from the control, along with $(\mathrm{g})$ corresponding schematic image, and $(\mathrm{h}-\mathrm{j})$ histographs with anti-luciferase staining, (k-n) $X$-gal staining, and (o-r) H\&E staining. (Used with permission from Shah, et al.: Molecular imaging of gene therapy for cancer. Gene Therapy 2004 11:1175-1187) 


\section{Cureus}

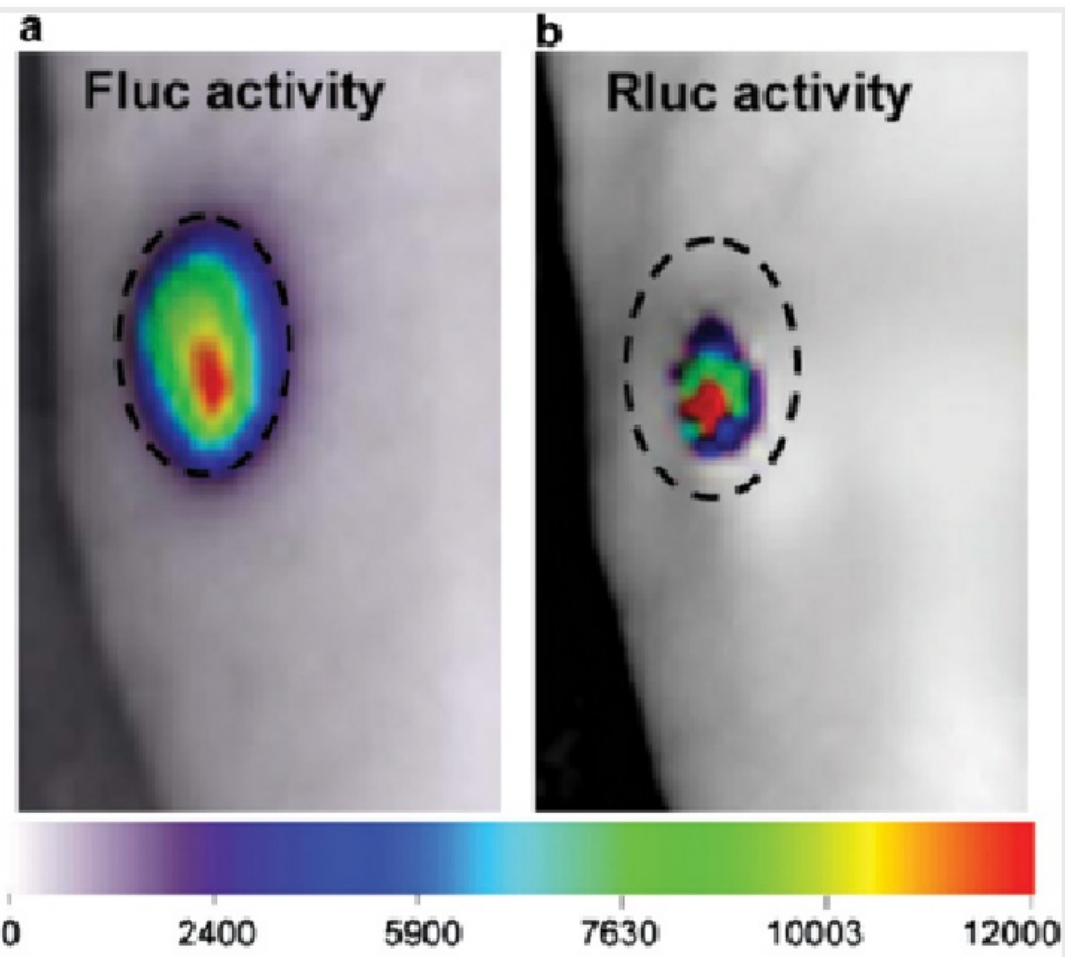

c
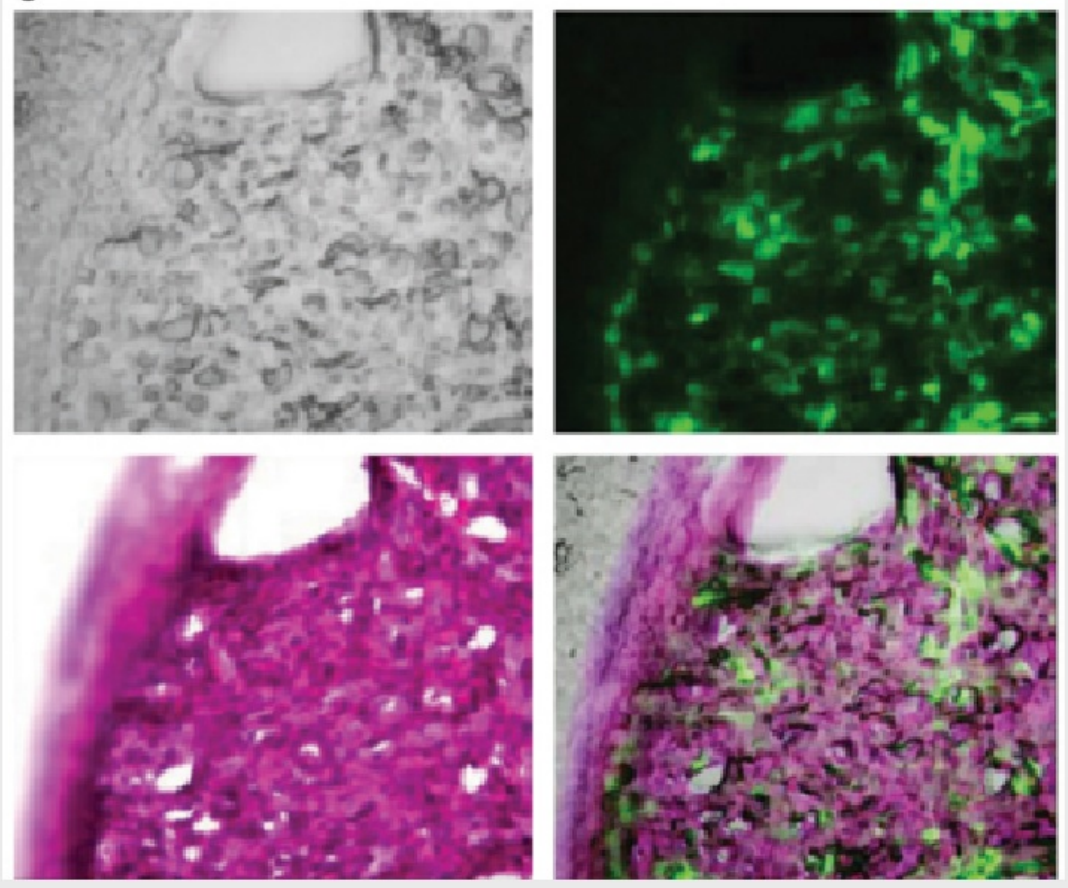

\section{FIGURE 5: Bioluminescence dual imaging of amplicon vector delivery and glioma volumes}

(a) Mouse model bearing subcutaneous Gli36fluc+ gliomas were injected i.p. with D-luciferin and imaged for Fluc activity. (b) A-Rluc amplicon vector injected into the same tumor and $36 \mathrm{~h}$ later, coelenterazine was injected into the tail vein and the mice were imaged for Rluc activity. The dashed circle around the tumor indicates the tumor periphery. (c) Histopathology showing tumor cells in the tissue sections, GFP-positive cells in the tumor; and H\&E stained tumor. (Used with permission from Shah, et al.: Molecular imaging of gene therapy for cancer. Gene Therapy 2004 11:1175-1187) 
The next main application of imaging genetics in medicine is to monitor gene therapy for bioavailability and to determine biodistribution and kinetic profiles. This will entail modalities that image deeper tissue, such as optoacoustics, ultrasound, MRI, and PET. The first gene therapy trial for the treatment of severe combined immunodeficiencies using the gene for adenosine deaminase took place in 1990 [17]. Since then, there has been a significant advancement in gene therapeutics, such as the introduction of an aerosol cystic fibrosis transporter gene [18], subretinal FLT1 therapy for age-related macular degeneration [19], GUC2YD gene therapy for Leber's amaurosis [20], intramuscular Factor IX therapy for hemophilia B [21], and intramuscular AAT gene therapy for hereditary emphysema [20], etc. Report gene imaging may also have a role in monitoring T-cell receptor expression in leukocytes, which is the key mechanism of gene-based immunomodulators used for cancer therapy [22].

\section{Conclusions}

Overall, reporter gene imaging is beginning to play an important role in expanding our understanding of disease mechanisms and in optimizing and developing new gene- and immunotherapy. As these novel approaches become clinically applied, notably the chimeric antigen receptor T-cell (CAR-T) therapy, the role of RG imaging appears to hold great promise as the driving force for genetic/precision medicine.

\section{Additional Information \\ Disclosures}

Conflicts of interest: In compliance with the ICMJE uniform disclosure form, all authors declare the following: Payment/services info: All authors have declared that no financial support was received from any organization for the submitted work. Financial relationships: All authors have declared that they have no financial relationships at present or within the previous three years with any organizations that might have an interest in the submitted work. Other relationships: All authors have declared that there are no other relationships or activities that could appear to have influenced the submitted work.

\section{References}

1. Youn H, Chung JK.: Reporter gene imaging. AJR Am J Roentgenol. 2013, 201:W206-14. 10.2214/AJR.13.10555

2. Brader P, Serganova I, Blasberg R: Noninvasive molecular imaging using reporter genes . J Nucl Med. 2013, 54:167-72. 10.2967/jnumed.111.099788

3. Ray P, Bauer E, Iyer M, Barrio JR, Satyamurthy N, Phelps ME, Herschman HR, Gambhir SS: Monitoring gene therapy with reporter gene imaging. Semin Nucl Med. 2001, 31:312-20.

4. Herschman HR: Noninvasive imaging of reporter gene expression in living subjects . Adv Cancer Res. 2004, 92:29-80. 10.1016/S0065-230X(04)92003-9

5. Gambhir SS, Barrio JR, Phelps ME, Iyer M, Namavari M, Satyamurthy N, Wu L, Green LA, Bauer E, MacLaren DC, Nguyen K, Berk AJ, Cherry SR, Herschman HR: Imaging adenoviraldirected reporter gene expression in living animals with positron emission tomography. Proc Natl Acad Sci U S A. 1999, 96:2333-38. 10.1073/pnas.96.5.2333

6. Sundaresan G, Yazaki PJ, Shively JE, Finn RD, Larson SM, Raubitschek AA, Williams LE, Chatziioannou AF, Gambhir SS, Wu AM: 124I-labeled engineered anti-CEA minibodies and diabodies allow high-contrast, antigen-specific small-animal PET imaging of xenografts in athymic mice. J Nucl Med. 2003, 44:1962-69.

7. Inubushi M, Tamaki $\mathrm{N}$ : Radionuclide reporter gene imaging for cardiac gene therapy . Eur J Nucl Med Mol Imaging. 2000, 34:S27-33. 10.1007/s00259-007-0438-X

8. Luker GD, Luker KE: Optical imaging: current applications and future directions. J Nucl Med. 
2008, 49:1-4. 10.2967/jnumed.107.045799

9. Taruttis A, Ntziachristos V: Translational optical imaging. AJR Am J Roentgenol. 2012, 199:263-71. 10.2214/AJR.11.8431

10. Vandsburger MH, Radoul M, Cohen B, Neeman M: MRI reporter genes: applications for imaging of cell survival, proliferation, migration and differentiation. NMR Biomed. 2013, 26:872-84. 10.1002/nbm.2869

11. Winter PM: Perfluorocarbon nanoparticles: evolution of a multimodality and multifunctional imaging agent. Scientifica (Cairo). 2014, 2014:746574. 10.1155/2014/746574

12. Prout DL, Silverman RW, Chatziioannou A: Detector concept for OPET - A combined PET and optical imaging system. IEEE Trans Nucl Sci. 2004, 51:752-56.

13. Nahrendorf M, Keliher E, Marinelli B, Waterman P, Feruglio PF, Fexon L, Pivovarov M, Swirski FK, Pittet MJ, Vinegoni C, Weissleder R: Hybrid PET-optical imaging using targeted probes . Proc Natl Acad Sci U S A. 2010, 107:7910-15. 10.1073/pnas.0915163107

14. Yaghoubi SS, Gambhir SS: PET imaging of herpes simplex virus type 1 thymidine kinase (HSV1-tk) or mutant HSV1-sr39tk reporter gene expression in mice and humans using [18F]FHBG. Nat Protoc. 2007, 1:3069 - 75. 10.1038/nprot.2006.459

15. Serganova I, Ponomarev V, Blasberg RG: Radionuclide-based reporter gene imaging: preclinical and clinical implementation and application. Nucl Med Rev. 2012, 15:C20-36.

16. Yaghoubi SS, Jensen MC, Satyamurthy N, Budhiraja S, Paik D, Czernin J, Gambhir SS: Noninvasive detection of therapeutic cytolytic T cells with 18F-FHBG PET in a patient with glioma. Nat Clin Pract Oncol. 2009, 6:53-58. 10.1038/ncponc1278

17. Kohn D: Gene therapy for XSCID: the first success of gene therapy . Pediatr Res. 2000, 48:578. 10.1203/00006450-200011000-00002

18. Burney TJ, Davies JC: Gene therapy for the treatment of cystic fibrosis . Appl Clin Genet. 2012, 5:29-36. 10.2147/TACG.S8873

19. Boye SE, Boye SL, Lewin AS, Hauswirth WW: A comprehensive review of retinal gene therapy . Mol Ther. 2013, 21:509-19. 10.1038/mt.2012.280

20. Nathwani AC, Reiss UM, Tuddenham EG, Rosales C, Chowdary P, McIntosh J, Della Peruta M, Lheriteau E, Patel N, Raj D, Riddell A, Pie J, Rangarajan S, Bevan D, Recht M, Shen YM, Halka KG, Basner-Tschakarjan E, Mingozzi F, High KA, Allay J, Kay MA, Ng CY, Zhou J, Cancio M, Morton CL, Gray JT, Srivastava D, Nienhuis AW, Davidoff AM: Long-term safety and efficacy of factor IX gene therapy in hemophilia B. N Engl J Med. 2014, 371:1994-2004. 10.1056/NEJMoa1407309

21. Stecenko AA, Brigham KL: Gene therapy progress and prospects: alpha-1 antitrypsin . Gene Therapy. 2003, 10:95-99. 10.1038/sj.gt.3301947

22. Rossig C, Brenner MK: Genetic modification of T lymphocytes for adoptive immunotherapy . Mol Ther. 2004, 10:5-18. 10.1016/j.ymthe.2004.04.014 